\title{
Cannabis and Endocrine system: A narrative review
}

\author{
Sharma $\mathbf{P}^{1}$, Balhara YPS ${ }^{2}$
}

1. Lecturer, Patan Academy of Health Sciences, School of Medicine, Lalitpur Nepal 2.Associate Professor, Department of Psychiatry, National Drug Dependence Treatment Centre, All India Institute of Medical Sciences (AIIMS), New Delhi, India

E-mail ${ }^{*}$ Corresponding author : pawan60@gmail.com

\begin{abstract}
Cannabis is one of the most abused substances worldwide. The active component of cannabis is THC which has multiple effects in the endocrine system in both animal models and humans. The interest of scientific community in endocrine effects of cannabis is recent. We present a narrative review of endocrine effects of cannabis in different organ system along with description of possible mechanism both in the animal models and as well as in humans. We also highlight the need of research in this area especially in the population of South East Asia.
\end{abstract}

Keywords: Cannabis, THC, Endocrine system

\section{BACKGROUND}

Archeological and historical findings from China indicate that cannabis plant was cultivated for fibers since 4.000 B.C which might be the record of oldest use of cannabis. ${ }^{1}$ The great social importance of cannabis reached in the second half of the 20th century as there was explosion of its consumption for hedonistic and recreational purpose. ${ }^{2}$ The cannabis gained interest of the scientific community leading to growth in literature after Gaoni and Mechoulam identified the structure of $\Delta^{9}$ Tetrahydrocannabinol (THC) in $1964 .^{3}$ This was then further intensified after the description and cloning of receptors specific for the cannabinoids in the nervous system and the isolation of an endogenous cannabinoid named anandamide subsquently. ${ }^{4}$

On the basis of use in the past year it has been estimated that the prevalence of use of cannabis is as high as $4.9 \%$ and around 128 to 232 million people use cannabis worldwide. ${ }^{5}$ In India according to national survey the prevalence of cannabis use was 3\% and ranked third common substance of abuse after alcohol and opioid to present in treatment setting. ${ }^{6}$ Cannabis is available in different names and form in our context; the dried leaves of cannabis plant known as "bhang", female flowering tops known as "ganja" and the resinous form known as "charas"7 Apart from being a substance of abuse there are some clinical conditions where cannabis and its analogue could be of therapeutic help. Some of the potential conditions are spastic disorders, pain, emesis, loss of appetite, epilepsy, glaucoma, bronchial asthma and mood disorders. ${ }^{8}$

The endocrine effects of cannabis have been a topic of interest from the last half of the century. It gained the light of research after Harmon and Aliapoulios provided the first description of marijuana-associated gynecomastia as an endocrine impact of cannabis use. ${ }^{9}$ Further investigation from the animal models has shown cannabis has widespread effects on multiple hormonal systems. Acute effects of cannabis is replicated in humans as well but the long term impact on the endocrine systems still remains unclear. ${ }^{10}$ This narrative review is aimed at looking into the endocrine effects of cannabis in different organ system along with description of possible mechanism both in the animal models and human. 


\section{HPA axis:}

The main function of HPA axis is to maintain the homeostatic balance in response to stress. Somatic or psychogenic stresses initiate a neuroendocrine cascade resulting in the release of pituitary adrenocorticotropin hormone (ACTH) in the central nervous system which results in the synthesis and secretion of glucocorticoids from the adrenal cortex. The regulation of ACTH secretion is in turn regulated by corticotropin releasing hormone (CRH) which is synthesized in the hypothalamic parvocellular paraventricular nuclei. Apart from exerting effects on metabolic and reproductive processes and on the immune system the glucocorticoids secreted in response to ACTH provide a negative feedback for regulation of the hypothalamic-pituitary-adrenal axis by inhibiting CRH and ACTH release.

\section{Animal Studies:}

It has been seen in the animal model that an acute administration of $\Delta^{9} \mathrm{THC}$ leads to increase in the glucocorticoid release within 30- $60 \mathrm{~min} \cdot{ }^{11}$ It was also found that administration of $\Delta^{9} \mathrm{THC}$ leads to rapid increase in plasma levels of ACTH and corticosterone within 20 minutes in ovariectomized rats. ${ }^{12}$ This increase in ACTH and corticosterone release are most likely due to increase in CRF release and not a direct pituitary action. This hypothesis is supported by the studies done in in hypophysectomized male rats where the stimulation of corticosterone release by $\Delta^{9}$ THC does not occur. ${ }^{13}$ However, isolated pituitary slices or dispersed pituitary cells with either $\Delta^{9}$ THC or the CB agonist WIN55212-2 doesn't have any effect on ACTH secretion, thus suggesting that there is no direct modulatory pathway of cannabinoids in ACTH release ${ }^{14}$

\section{Human Studies:}

In the human subjects, a similar effect of increased cortisol release is seen in response to the intravenous use of cannabis. $\Delta-9$-THC when given intravenously; raised the plasma cortisol levels and this raise in levels was dosedependent in both cannabis dependent individuals and controls, however, in case of frequent users, blunted response is seen as compared to healthy controls. ${ }^{15} 1617$ In other studies it is seen that there is no change in the cortisol or ACTH level after the oral administration of cannabis in chronic users, new users or in the placebo group..$^{18}$ There is some evidence that there is HPA axis hypo-activity at the time of morning awakening in adolescents who have early onset of cannabis use compared to late onset users. This finding might indicate an increased risk for early users of seeking stimulation to restore arousal levels by using substances which is an indirect way of saying that cannabis increases the cortisol level. ${ }^{20}$

\section{Thyroid Hormone:}

The thyroid hormone has major contribution in the cellular metabolism. The secretion of thyroid hormone is regulated by Thyroid Stimulating Hormone (TSH) which ultimately is controlled by thyrotropin-releasing hormone (TRH). It is seen that there are functional CB1 cannabinoid receptors organized along the central and peripheral thyroid hormone axis. ${ }^{21}$

\section{Animal Studies:}

The first report of action of cannabis in thyroid hormone was collected as early as 1965 where there was decrease of iodine accumulation in thyroid gland.22 The levels of thyroxin and TSH are significantly decreased for a short duration after acute administration of THC in rodents. Similarly, cannabis extract has shown to decrease the release of radioactive iodine from the thyroid. When exogenous TSH is administered, these effects are reversed suggesting a pituitary site of action. When THC is chronically administered the depressant effect of cannabinoids in thyroid is lost suggesting some amount of tolerance. ${ }^{23}{ }^{24}$ Intraperitoneal injection of THC in rats also leads to significant decrease in TSH, T3 and T4 hormone, however, the pituitary or thyroid response to exogenous thyrotropin releasing hormone given exogenously is not affected by THC. ${ }^{25}$ The available evidence points towards the pituitary gland as only site of action for THC.

\section{Human Studies:}

Research on human have shown subtle lower levels of T4 in chronic cannabis users compared to other users and control subjects; but all of these values were within the standard range. ${ }^{26}$ In another study involving 39 cannabis dependent individual it was seen that the thyroid hormones was within the population range and it didn't correlate with the level of THC, THC-OH or THC-COOH in serum. ${ }^{27}$ The action of cannabis on thyroid hormone in human is yet to be concluded. 


\section{Growth Hormone:}

Apart from growth, the growth hormone helps in many aspects of metabolism and general wellbeing. It is secreted by anterior pituitary and is stimulated by growth hormone releasing hormone (GHRH) whereas, somatostatin inhibits its release.

\section{Animal Studies:}

In the animal model it is seen that the administration of $\Delta-9-T H C$ lead to decrease in $\mathrm{GH}$ level acting as a stressor in the neuroendocrine system. ${ }^{28}$ The decrease in the growth hormone seems to be of differential nature on administration of different cannabinoids. ${ }^{29}$ Similarly a synthetic cannabinoid, HU-120, when administered in rats leads to dose dependent inhibition of the growth hormone. ${ }^{30}$

\section{Human Studies:}

There are very few studies investigating the effect of cannabis on GH secretion in humans. In one of the studies by Benowitz et al 31, it was seen that that 4 days of oral THC in individuals with insulin-induced hypoglycemia lead to blunting of the normal GH response. A study done in four male revealed increase in growth hormone level after cannabis use. ${ }^{17}$ Use of cannabis during pregnancy leads to impaired fetal growth which might be an indirect evidence for the effect on growth hormone. ${ }^{32}$

\section{Male reproductive hormones:}

Testosterone secreted by Leydig cells is under the control of $\mathrm{LH}$ and it has multiple actions including maintenance of secondary sex characters, whereas FSH acts on sertoli cells to regulate spermatogenesis.

\section{Animal Studies:}

In animal studies administration of THC leads to significant decrease in testosterone concentration as evidenced from the studies in rhesus monkey. ${ }^{33}$ There is decreased weight and decreased testosterone formation by rat testis. ${ }^{34}$ It was later hypothesized it may be the result of THC's effects on the hypothalamo-hypophyseal area. THC reduces gonadotropin levels causing reduction in cytochrome P-450 of interstitital cell microsomal system which is needed for the synthesis testosterone. ${ }^{35}$ The effects on the testosterone level in animal studies seem to have tolerance which is explained on the basis of down regulation of $\mathrm{CB} 1$ receptors after multiple exposures. ${ }^{36}$ In animal models it is also seen that the CB1 receptors are also present in testes. ${ }^{37}$ Not only has this, cannabis (THC) also inhibited the binding of dihydrotestosterone to the androgen receptors. ${ }^{38}$ Thus, these evidences conclude that the action of THC is not only at the central level but also at the testicular level.

\section{Human Studies:}

The human studies in this regard are conflicting. Some reports have shown decrease, and some have shown no change in the hormone level. Most of the studies in this aspect come from the 70 s and 80 s and are not conclusive. In a study done in 1974 in 17 male subject it was seen that the chronic use of cannabis lead to decrease in the plasma testosterone level. ${ }^{39}$ Another study which examined the testosterone level before, during and after chronic cannabis use showed no significant alteration in the testosterone level. ${ }^{40}$ More recent study have shown nonsignificant depression of testosterone level. ${ }^{17}$ Other studies also have shown the normal level in cannabis users both occasional as well as chronic users. ${ }^{41} 424344$ However, on the other hand it is seen that the higher level of testosterone is a predictor of the cannabis use. ${ }^{45}$ Even with the normal testosterone level oligospermia has been seen with the chronic use of cannabis and few cases of impotency have also been reported. ${ }^{39}$ Apart from that other studies also have found the decrease in the sperm concentration as well as morphology in cannabis users. These changes seem to be reversible..$^{46}$ So, in a nutshell from the studies, though the level of testosterone show inconspicuous reports; the changes in the sperm morphology seems to be significant, hence concluding the action of cannabis in male reproductive part is central as well as peripheral i.e. at the testicular level.

\section{Female Reproductive System:}

LH and FSH secreted from anterior pituitary control the female reproductive system. At the end of menstruation, the level of progesterone and estrogen wanes leading to increase of FSH level which in turn stimulates growth and development of ovarian follicle. The rising estrogen after that has negative feedback on both LH and FSH. Peak estrogen causes LH 
surge and ovulation subsequently. The corpus luteum produces estrogen and progesterone under the influence of LH. The discussion about the effects of cannabis in the reproductive system and hormone production was a matter of great interest in $70 \mathrm{~s}$ and $80 \mathrm{~s}$ as evidenced by the literature.

\section{Animal Studies:}

Administration of THC have led to decrease in progesterone level in female rat during the luteal phase of estrous cycle. ${ }^{48} 49$ Many studies demonstrated that there is decrease in the secretion of LH and FSH acutely after the administration of THC and would delay the ovulation in female rats. ${ }^{50} 5152$ Even the low dose of THC delays the onset of puberty and the post pubertal reproductive functions in female rats and this effect of THC seems to be of long-term and irreversible nature. ${ }^{53}$ The same finding was seen even in the ovariectomized rats suggesting the central endocrine mechanism. ${ }^{54}$ Apart from this the studies in the rhesus monkey have also shown decrease in the level of LH and FSH after the administration of single dose of THC and the effect seems to be of central action. ${ }^{55}$ There is evidence of presence of CB1 receptors in ovary as well. ${ }^{56}$ The crude marijuana extract, condensed marijuana smoke competes with estradiol for binding to the estrogen receptor, but pure delta 9-tetrahydrocannabinol doesn't not interact with the estrogen receptor. Among many common cannabinoids tested, only cannabidiol had some binding with the estrogen receptor. ${ }^{57}$ These few findings lead a credence to the concept of some peripheral action of cannabis at ovary. It has also been said that the female of many species are more sensitive to the effects of THC than male. ${ }^{58}$ However, tolerance develops in the disruptive effect of THC in estrous cycle in female primates. ${ }^{59} 60$

\section{Human Studies:}

The effect of THC in human female population is not as clear as in the animal model. A single dose of cannabis $(1 \mathrm{~g})$ induces a $30 \%$ suppression in LH level during luteal phase. ${ }^{61}$ A study done in 16 female have shown small but statistically significant decrement in LH level, however, all $\mathrm{LH}$ levels were within the normal range for healthy adult women and biologically insignificant. In the same study there was no evidence of any dose-related suppression of ovulation or change of luteal phase function in women with heavy, moderate or occasional marihuana smokers. This indicate that smoking cannabis at the dose levels observed for 21 days doesn't disturb the menstrual cycle in healthy adult women. ${ }^{62}$ Another study has shown increase in LH level as well. ${ }^{63}$ Yet another study by the same author has shown no change in $\mathrm{LH}$ level after smoking of cannabis in menopausal women. ${ }^{64}$ However, the direct action of cannabis in the ovary haven't been demonstrated.

\section{Reproduction:}

\section{Animal Studies:}

Postnatal mortality is increased and neonatal weight decreased at 21 days after treatment with cannabis in female rats. ${ }^{65}$ TLC administration in prepubertal rats when given in small doses too have long term irreversible alteration in reproductive function. ${ }^{53}$ Abortion and still birth in rats and rhesus monkey was also seen in few cases when THC was administered in early pregnancy. ${ }^{66} 67$ Apart from that it also has teratogenic and embryocidal property in animals. ${ }^{68}$ At a genetic level sex steroids control the expression of the CB1 gene in the anterior pituitary gland of both male and female rats. So, we can speculate that a regulatory mechanism is operational in the reproductive organ. ${ }^{69}$

\section{Human Studies:}

In human studies it is seen that cannabis use has been correlated with low birth weight and prematurity..$^{70} 71$ There is a negative impact of cannabis intake in the mid-gestational fetal growth after adjusting for maternal use of other substance. ${ }^{72}$ Further, in chronic cannabis user dose dependent lower gestational age is seen. ${ }^{73}$ There is an emerging body of evidence indicating that marijuana may cause problems with neurological development, resulting in hyperactivity, and poor cognitive function. ${ }^{74}$ Current understanding suggests that endogenous and exogenous cannabinoids may be critical in the areas of embryo implantation and miscarriage. It is clear that cannabis-based substances and compounds that might interact with endocannabinoid synthesis are contraindicated during pregnancy. ${ }^{75}$ A metaanalysis is planned to assess the effects of prenatal exposure to cannabis on pregnancy outcomes; after which a clear evidence can be presented in this font. ${ }^{76}$ 


\section{Erectile/Sexual Function:}

Cannabis is regarded as one of the important causes of erectile dysfunction. ${ }^{77}$ However, the recent studies have failed to find any association between frequency of cannabis use and problems in erection as evidenced in 8656 Australians where 754 had cannabis use ${ }^{78}$ and also from a population based study from Morocco. ${ }^{79}$ Similar findings were seen in the study by Johnson and colleagues where there was no association between lifetime cannabis use and lack of erection in men or lack of arousal for women. However, there was some relation between cannabis use and inhibited orgasm; a history of cannabis use was associated with a reporting of an inability to orgasm. ${ }^{80}$ Other studies too support that high doses of cannabis might lead to "inability to perform" and that this may be related to changes in plasma testosterone level; modest doses lead to increase in plasma testosterone level but high doses lower testosterone below baseline. ${ }^{81}$ It is also seen that cannabis use being associated with an increased duration of intercourse and decreased number of orgasms. ${ }^{82}$ A study by Aversa et al. has shown that endothelial dysfunction as a result of chronic cannabis use might be the marker of vasculogenic erectile dysfunction. ${ }^{83}$ So, overall speaking there is some effect of cannabis in male sexual function but the studies are limited in both quality and quantity and the results are conflicting and contradictory. ${ }^{84}$

\section{Prolactin:}

Prolactin initially regarded as anterior pituitary hormone is also synthesized within the central nervous system, the immune system, the uterus and its associated tissues of conception, and even the mammary gland itself has a major function of stimulating milk production and maintaining lactation in human after child birth. It also controls the variety of behaviors and even the homeostasis. ${ }^{85}$ It is inhibited by dopamine. ${ }^{86}$ Animal Studies:

The studies in animal models have demonstrated acute reduction in prolactin level after administration of THC. ${ }^{87} 88$ The decrease in the prolactin level are not consistent in all studies. This decrease seem to be dependent on the stage of ovulatory cycle. ${ }^{89}$ Apart from this, in one of the studies, it was seen that there was biphasic response showing initial increment in the prolactin level followed by significant decrease after administration of THC. This study concluded a direct effect on hypothalamic structures having cannabinoid receptors small in quantity but very active..$^{90}$ More recently it has been shown that the effect on prolactin is due to direct action on CNS rather than on the pituitary gland as evidenced by the failure of THC to alter tonic PRL secretion in hypophysectomized/pituitary-autografted rats or PRL release from pituitary tissue in vitro. ${ }^{91}$ However, some evidence of no change in the prolactin level with administration of THC are also present. ${ }^{92}$

\section{Human Studies:}

In human female it has been seen the prolactin level decreases acutely on administration of THC but in the luteal phase of menstrual cycle as evidenced in the study of 16 healthy females. ${ }^{93}$ But both acute and chronic smoking of cannabis in male had no effect in the prolactin level when compared to healthy male. ${ }^{94} 95$ Same findings have been replicated in female as well. ${ }^{18}$ The frequent users have lower baseline plasma prolactin levels relative to healthy controls as evidenced from the pooled data in which intravenous $\Delta-9$-THC was given in 36 healthy controls and 40 frequent cannabis users .${ }^{16}$ One of the large studies in both male and female have shown no significant change in prolactin level. ${ }^{18}$

\section{Obesity/Weight Gain and glucose metabolism:} Animal model:

The review of studies published between 1965 to 1975 by Abel have found that, out of 25 experiments only three studies showed increase in the weight after cannabis intake. ${ }^{96}$ However, after the discovery of cannabinoid receptors, most research has shown hyperphagic action of THC. ${ }^{97}$ This hyperphagic action of THC seems to be mediated by CB1 cannabinoid receptors as evidenced by the THC induced hyperphagic feeding being reversed by the selective CB1 antagonist rimonabant, but not by the CB2selective antagonist SR144258. ${ }^{98}$ Anandamide and 2AG when administered into the shell of nucleus accumbens and hypothalamic nuclei leads to increased appetite in animal models 
suggesting the effect on the eating motivation ${ }^{99}$ 100 . Hence, it can be said that use of cannabis in animals lead to obesity as evidenced from the hyperphagia. Colombo et al. (1998) have shown that that daily administration of rimonabant, an inverse agonist of CB1 receptor, suppresses intake of lab chow and induces weight loss in rats in persistent manner. ${ }^{101}$ Vickers et al. (2003) also demonstrated that oral treatment with rimonabant decreases food intake along with gain in body weight (both in lean and genetically obese Zucker (fa/fa rats) in dosedependent manner. Reduction in body weight is more in case of obese rats. ${ }^{102}$ This an indirect evidence to the relationship of cannabis and feeding as well as weight gain. Similarly, it is a known fact that the cannabinoid receptors and their endocannabinoid ligands play a significant role in regulating glucose hemostasis, appetite, insulin sensitivity and pancreatic $\beta$-cell function. ${ }^{14}$ Cannabis intake in different dosage leads to increase in the blood glucose level and decrease in the glucose tolerance in animal models. ${ }^{103}$

\section{Human Studies:}

The first systematic study published as early as 1976 by Greenberg et al. has shown that there is increase in both energy intake and weight after the intake of cannabis. It was also shown that body weight continued to increase even after energy intake was stabilized. ${ }^{104}$ In other studies too it was seen that cannabis increased total food intake. The food components that had significant increments were sweet solid snack items such as candy bars, cookies and cakes. ${ }^{105}$ 106 The probable mechanism of increased food intake is CB1 receptor mediated as the $\mathrm{CB}_{1}$ cannabinoid receptor antagonist SR141716 (rimonabant) reduces food intake after systemic administration in animals and the same molecule also leads to the reversal of most of the psychological and physiological effects of cannabis. ${ }^{107}$ This has also been tested in humans in the conditions involving wasting and severe appetite loss like cancer cachexia and AIDS where the treatment with THC (synthetic form, Dronabinol) leads to improvement in both ratings of appetite and actual consumption level of food. However, the trials are hampered by the serious nature of illness. ${ }^{108}$ In a recent study by Strat and Le Foll where the authors took the data from 2 representative epidemiologic studies of US adults aged 18 years or older namely the National Epidemiologic Survey on Alcohol and Related Conditions (NESARC; 2001-2002) and the National Comorbidity Survey-Replication (NCS-R; 2001-2003), and estimated the prevalence of obesity as a result of cannabis use. They found that prevalence of obesity to be lower in cannabis users than in nonusers. ${ }^{109}$ This study was in contrast to the other studies of the similar nature which had shown frequent use of cannabis to be associated with obesity in girls taking nationally representative sample $(\mathrm{n}=7885) .{ }^{110}$ Another study showed that use of cannabis is associated with a higher intake of calories but is not associated with a higher BMI suggesting no role in obesity. ${ }^{111}$ Thus, the role of cannabis as an associated factor in obesity is still controversial. It is a known fact that the cannabinoid receptors and their endocannabinoid ligands play a significant role in regulating glucose hemostasis, appetite, insulin sensitivity and pancreatic $\beta$-cell function. ${ }^{14}$ It is seen that in healthy human volunteers, the acute treatment with cannabis leads to impaired intolerance. ${ }^{112} 113$ In a study with a sample of 4657 , in multivariable adjusted models it was seen that current marijuana use was associated with $16 \%$ lower fasting insulin levels and $17 \%$ lower homeostasis model assessment of insulin resistance. There was also significant association marijuana use and smaller waist circumferences. This result is in contrast to the other physiological effects like weight gain and impaired glucose tolerance. However, the authors do not comment on the mechanism. ${ }^{114}$ In another study of 30 cases and 30 controls it was seen that chronic cannabis smoking had association with visceral adiposity and insulin resistance of adipose tissue but no association was seen with insulin insensitivity, impaired pancreatic $\beta$ cell function or glucose intolerance. ${ }^{115}$ The CARDIA, 15 years of longitudinal study too didn't find any significant change in the glucose level in the patients who took cannabis. ${ }^{111}$ These finding has also been supported by other studies that found the lower prevalence of diabetes in the cannabis users. The authors have postulated that there could be a role of anti-inflammatory properties of cannabinoids of marijuana that modify inflammation probably through the 
inhibitory actions on prostaglandins and COX2.116

\section{CONCLUSION:}

Cannabis as well as its active component THC has multiple effects in the endocrine system in both animal models as well as in humans. Most of the effect can be summarized as depressant of almost all hormones; however, some inconspicuous reports have been seen. Like other effects the tolerance has been seen to develop with chronic administration. Variation in study designs, stage of human development, and clear cut lack of a definite cohort has produced inconsistent results in human population. The clinical consequences and a long-term effect seem to be subtle. The research from South East Asia is limited in this regard and further studies are warranted from this part of the world.

\section{ACKNOWLEDGEMENT: None}

\section{CONFLICT OF INTEREST: None}

\section{REFERENCES:}

1. Li H-L. An archaeological and historical account of cannabis in China. Econ Bot. 1973;28(4):437-448. doi:10.1007/BF02862859.

2. Zuardi AW. History of cannabis as a medicine: a review. Rev Bras Psiquiatr. 2006;28(2):153-157. doi:10.1590/S1516-44462006000200015.

3. Gaoni Y, Mechoulam R. Isolation, structure, and partial synthesis of an active constituent of hashish. J Am Chem Soc. 1964;86(8):1646-1647.

4. Martin BR, Mechoulam R, Razdan RK. Discovery and characterization of endogenous cannabinoids. Life Sci. 1999;65(6-7):573-595. doi:10.1016/S00243205(99)00281-7.

5. WDR 2015 - Use of drugs. Tableau Software. http://public.tableau.com/views/WDR2015Useofdrugs/Preview/ Accessed November 9, 2015.

6. Ray R. The Extent, Pattern and Trends of Drug Abuse in India: National Survey. Ministry of Social Justice and Empowerment, Government of India $\mathcal{E}$ United Nations Office on Drugs and Crime, Regional Office for South Asia; 2004.

7. Touw M. The religious and medicinal uses of Cannabis in China, India and Tibet. J Psychoactive Drugs. 1981;13(1):23-34. doi:10.1080/02791072.1981.10471447.

8. Kumar RN, Chambers WA, Pertwee RG. Pharmacological actions and therapeutic uses of cannabis and cannabinoids. Anaesthesia.
2001;56(11):1059-1068.

doi:10.1111/j.13652044.2001.02269.x.

9. Harmon J, Aliapoulios MA. Gynecomastia in marihuana users. N Engl J Med. 1972;287(18):936. doi:10.1056/NEJM197211022871824.

10. Brown TT, Dobs AS. Endocrine Effects of Marijuana. J Clin Pharmacol. 2002;42(S1):90S - 965. doi:10.1002/j.1552-4604.2002.tb06008.x.

11. Puder M, Weidenfeld J, Chowers I, Nir I, Conforti N, Siegel RA. Corticotrophin and corticosterone secretion following $\Delta 1$-tetrahydrocannabinol, in intact and in hypothalamic deafferentated male rats. Exp Brain Res. 2013;46(1):85-88. doi:10.1007/BF00238101.

12. Jackson AL, Murphy LL. Role of the hypothalamicpituitary-adrenal axis in the suppression of luteinizing hormone release by delta-9-tetrahydrocannabinol. Neuroendocrinology. 1997;65(6):446-452.

13. Kubena RK, Perhach JL, Barry H. Corticosterone elevation mediated centrally by delta 1tetrahydrocannabinol in rats. Eur J Pharmacol. 1971;14(1):89-92.

14. Pagotto U, Marsicano G, Cota D, Lutz B, Pasquali R. The emerging role of the endocannabinoid system in endocrine regulation and energy balance. Endocr Rev. 2006;27(1):73-100. doi:10.1210/er.2005-0009.

15. D'Souza DC, Ranganathan $M$, Braley $G$, et al. Blunted Psychotomimetic and Amnestic Effects of $\Delta-9$ Tetrahydrocannabinol in Frequent Users of Cannabis. Neuropsychopharmacol Off Publ Am Coll Neuropsychopharmacol. 2008;33(10):2505-2516. doi:10.1038/sj.npp.1301643.

16. Ranganathan M, Braley G, Pittman B, et al. The effects of cannabinoids on serum cortisol and prolactin in humans. Psychopharmacology (Berl). 2009;203(4):737744. doi:10.1007/s00213-008-1422-2.

17. Cone EJ, Johnson RE, Moore JD, Roache JD. Acute effects of smoking marijuana on hormones, subjective effects and performance in male human subjects. Pharmacol Biochem Behav. 1986;24(6):1749-1754. doi:10.1016/0091-3057(86)90515-0.

18. Block RI, Farinpour R, Schlechte JA. Effects of chronic marijuana use on testosterone, luteinizing hormone, follicle stimulating hormone, prolactin and cortisol in men and women. Drug Alcohol Depend. 1991;28(2):121-128. doi:10.1016/0376-8716(91)90068A.

19. Dax EM, Pilotte NS, Adler WH, Nagel JE, Lange WR. The effects of 9-ene-tetrahydrocannabinol on hormone release and immune function. I Steroid Biochem. 1989;34(1-6):263-270.

20. Huizink AC, Ferdinand RF, Ormel J, Verhulst FC. Hypothalamic-pituitary-adrenal axis activity and early onset of cannabis use. Addict Abingdon Engl. 2006;101(11):1581-1588. doi:10.1111/j.13600443.2006.01570.x.

21. Porcella A, Marchese G, Casu MA, et al. Evidence for functional CB1 cannabinoid receptor expressed in the rat thyroid. Eur J Endocrinol Eur Fed Endocr Soc. 2002;147(2):255-261. 
22. Miras CJ. Some aspects of cannabis action. Hashish Its Chem Pharmacol. 1965:37-47.

23. Lomax $P$. The effect of marihuana on pituitary-thyroid activity in the rat. Agents Actions. 1970;1(5):252-257.

24. Nazar B, Kairys DJ, Fowler R, Harclerode J. Effects of delta9-tetrahydrocannabinol on serum thyroxine concentrations in the rat. J Pharm Pharmacol. 1977;29(12):778-779.

25. Hillard CJ, Farber NE, Hagen TC, Bloom AS. The effects of $\delta 9$-tetrahydrocannabinol on serum thyrotropin levels in the rat. Pharmacol Biochem Behav. 1984;20(4):547-550. doi:10.1016/00913057(84)90303-4.

26. Herning RI, Better W, Cadet JL. EEG of Chronic Marijuana Users during Abstinence: Relationship to Years of Marijuana Use, Cerebral Blood Flow and Thyroid Function. Clin Neurophysiol Off J Int Fed Clin Neurophysiol. 2008;119(2):321-331. doi:10.1016/j.clinph.2007.09.140.

27. Bonnet $U$. Chronic cannabis abuse, delta-9tetrahydrocannabinol and thyroid function. Pharmacopsychiatry. 2013;46(1):35-36. doi:10.1055/s0032-1316342.

28. Kokka N, Garcia JF. Effects of delta 9-THC on growth hormone and ACTH secretion in rats. Life Sci. 1974;15(2):329-338.

29. Dalterio SL, Michael SD, Macmillan BT, Bartke A. Differential effects of cannabinoid exposure and stress on plasma prolactin, growth hormone and corticosterone levels in male mice. Life Sci. 1981;28(7):761-766. doi:10.1016/0024-3205(81)901582.

30. Martín-Calderón JL, Muñoz RM, Villanúa MA, et al. Characterization of the acute endocrine actions of (-)11-hydroxy- $\Delta 8$-tetrahydrocannabinol-dimethylheptyl (HU-210), a potent synthetic cannabinoid in rats. Eur J Pharmacol. 1998;344(1):77-86. doi:10.1016/S00142999(97)01560-4.

31. Benowitz NL, Jones RT, Lerner CB. Depression of Growth Hormone and Cortisol Response to InsulinInduced Hypoglycemia After Prolonged Oral Delta-9Tetrahydrocannabinol Administration in Man. J Clin Endocrinol Metab. 1976:42(5):938-941. doi:10.1210/jcem-42-5-938.

32. Zuckerman B, Frank DA, Hingson $R$, et al. Effects of maternal marijuana and cocaine use on fetal growth. $N$ Engl I Med. 1989;320(12):762-768. doi:10.1056/NEJM198903233201203.

33. Smith CG, Moore CE, Besch NF, Besch PK. Effect of marihuana (delta-9 tetrahydrocannabinol) on secretion of sex-hormones in mature male rhesus-monkey. In: Clinical Chemistry. Vol 22. Amer Assoc Clinical Chemistry 2101 l street NW, suite 202, Washington, DC 20037-1526; 1976:1184-1184.

34. Harclerode I, Nyquist SE, Nazar B, Lowe D. Effects of cannabis on sex hormones and testicular enzymes of the rodent. Adv Biosci. 1978;22-23:395-405.

35. List A, Nazar B, Nyquist S, Harclerode J. The effects of delta9-tetrahydrocannabinol and cannabidiol on the metabolism of gonadal steroids in the rat. Drug Metab Dispos. 1977;5(3):268-272.

36. Dixit VP, Sharma VN, Lohiya NK. The effect of chronically administered cannabis extract on the testicular function of mice. Eur J Pharmacol. 1974;26(1):111-114. doi:10.1016/0014-2999(74)900818.

37. Gérard CM, Mollereau C, Vassart G, Parmentier M. Molecular cloning of a human cannabinoid receptor which is also expressed in testis. Biochem J. 1991;279(Pt 1):129-134.

38. Purohit V, Ahluwahlia BS, Vigersky RA. Marihuana inhibits dihydrotestosterone binding to the androgen receptor. Endocrinology. 1980;107(3):848-850. doi:10.1210/endo-107-3-848.

39. Kolodny RC, Masters WH, Kolodner RM, Toro G. Depression of plasma testosterone levels after chronic intensive marihuana use. $N$ Engl J Med. 1974;290(16):872-874. doi:10.1056/NEJM197404182901602.

40. Mendelson JH, Kuehnle J, Ellingboe J, Babor TF. Plasma Testosterone Levels before, during and after Chronic Marihuana Smoking. N Engl J Med. 1974;291(20):1051-1055. doi:10.1056/NEJM197411142912003.

41. Barnett G, Chiang C-WN, Licko V. Effects of marijuana on testosterone in male subjects. J Theor Biol. 1983;104(4):685-692. doi:10.1016/00225193(83)90255-2.

42. Cushman P. Plasma Testosterone Levels in Healthy Male Marijuana Smokers. Am J Drug Alcohol Abuse. 1975;2(2):269-275. doi:10.3109/00952997509002740.

43. G F, W N, T A. [Serum testosterone concentrations in cannabis and opiate users]. Beitr Gerichtl Med. 1989;48:57-66.

44. Mendelson JH, Ellingboe J, Kuehnle JC, Mello NK. Effects of chronic marihuana use on integrated plasma testosterone and luteinizing hormone levels. I Pharmacol Exp Ther. 1978;207(2):611-617.

45. Tarter RE, Kirisci L, Gavaler JS, et al. Prospective Study of the Association Between Abandoned Dwellings and Testosterone Level on the Development of Behaviors Leading to Cannabis Use Disorder in Boys. Biol Psychiatry. 2009;65(2):116-121. doi:10.1016/j.biopsych.2008.08.032.

46. Nahas GG. Marihuana: Chemistry, Biochemistry, and Cellular Effects. Springer Science $\mathcal{E}$ Business Media; 2012.

47. 3rd HW, Gg N, P Z, Hf H. Changes in human spermatozoa associated with high dose marihuana smoking. Adv Biosci. 1977;22-23:429-439.

48. S B, Sa H, Ts S. Cannabinoid inhibition of rat luteal cell progesterone synthesis. Res Commun Chem Pathol Pharmacol. 1979;24(2):413-416.

49. Kostellow AB, Ziegler D, Kunar J, Fujimoto GI, Morrill GA. Effect of cannabinoids on estrous cycle, ovulation and reproductive capacity of female A/J mice. Pharmacology. 1980;21(1):68-75. 
50. Ayalon D, Nir I, Cordova T, et al. Acute effect of delta1-tetrahydrocannabinol on the hypothalamopituitary-ovarian axis in the rat. Neuroendocrinology. 1977;23(1):31-42.

51. Sl D, Dl M, A B. Effects of delta 9-THC on plasma hormone levels in female mice. Subst Alcohol Actions Misuse. 1982;4(5):339-345.

52. Chakravarty I, Shah PG, Sheth AR, Ghosh JJ. Mode of action of delta-9-tetrahydrocannabinol on hypothalamo-pituitary function in adult female rats. J Reprod Fertil. 1979;57(1):113-115.

53. Wenger T, Croix D, Tramu G. The effect of chronic prepubertal administration of marihuana (delta-9tetrahydrocannabinol) on the onset of puberty and the postpubertal reproductive functions in female rats. Biol Reprod. 1988;39(3):540-545.

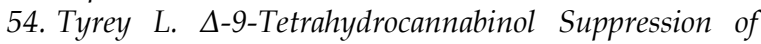
Episodic Luteinizing Hormone Secretion in the Ovariectomized Rat. Endocrinology. 1978;102(6):1808-1814. doi:10.1210/endo-102-6-1808.

55. Cg $S, N f B, \operatorname{Rg} S, P k B$. Effect of tetrahydrocannabinol on the hypothalamic-pituitary axis in the ovariectomized rhesus monkey. Fertil Steril. 1979;31(3):335-339.

56. Galiègue S, Mary S, Marchand J, et al. Expression of central and peripheral cannabinoid receptors in human immune tissues and leukocyte subpopulations. Eur J Biochem FEBS. 1995;232(1):54-61.

57. Sauer MA, Rifka SM, Hawks RL, Cutler GB, Loriaux $D L$. Marijuana: interaction with the estrogen receptor. J Pharmacol Exp Ther. 1983;224(2):404-407.

58. Drug Effects on Neuroendocrine Regulation. Elsevier; 1973.

59. Smith CG, Almirez RG, Berenberg J, Asch RH. Tolerance develops to the disruptive effects of delta 9tetrahydrocannabinol on primate menstrual cycle. Science. 1983;219(4591):1453-1455. doi:10.1126/science.6298938.

60. Sassenrath EN, Chapman LF, Goo GP. Reproduction in rhesus monkeys chronically exposed to delta-9tetrahydrocannabinol. Adv Biosci. 1978;22-23:501512.

61. Mendelson JH, Mello NK, Ellingboe J, Skupny AS, Lex BW, Griffin M. Marihuana smoking suppresses luteinizing hormone in women. J Pharmacol Exp Ther. 1986;237(3):862-866.

62. Mendelson JH, Mello NK. Marihuana Effects on Pituitary and Gonadal Hormones in Women. In: DSc GGNM, MS KMSM, Harvey D, DSc SA PharmD, $M D N P, M D R C$, eds. Marihuana and Medicine. Humana Press; 1999:385-392. http://link.springer.com/chapter/10.1007/978-1-59259710-9_39. Accessed October 15, 2015.

63. Mendelson JH, Mello NK. Effects of marijuana on neuroendocrine hormones in human males and females. NIDA Res Monogr. 1984;44:97-114.

64. Mendelson JH, Cristofaro P, Ellingboe J, Benedikt $R$, Mello NK. Acute effects of marihuana on luteinizing hormone in menopausal women. Pharmacol Biochem Behav. 1985;23(5):765-768.

65. Abel EL, Dintcheff BA, Day N. Effects of marihuana on pregnant rats and their offspring. Psychopharmacology (Berl). 1980;71(1):71-74. doi:10.1007/BF00433255.

66. El A. Effects of delta 9-THC on pregnancy and offspring in rats. Neurobehav Toxicol Teratol. 1983;6(1):29-32.

67. Rh A, Cg S. Effects of delta 9-THC, the principal psychoactive component of marijuana, during pregnancy in the rhesus monkey. J Reprod Med. 1986;31(12):1071-1081.

68. Rosenkrantz $H$. Effects of Cannabis on Fetal Development of Rodents. In: DSc GGNM, MS KMSM, Harvey D, DSc SA PharmD, MD NP, MD RC, eds. Marihuana and Medicine. Humana Press; 1999:411-430.

http://link.springer.com/chapter/10.1007/978-1-59259710-9_41. Accessed October 18, 2015.

69. González S, Bisogno T, Wenger T, et al. Sex Steroid Influence on Cannabinoid CB1 Receptor mRNA and Endocannabinoid Levels in the Anterior Pituitary Gland. Biochem Biophys Res Commun. 2000;270(1):260-266. doi:10.1006/bbrc.2000.2406.

70. Sherwood RA, Keating J, Kavvadia V, Greenough A, Peters TJ. Substance misuse in early pregnancy and relationship to fetal outcome. Eur J Pediatr. 1999;158(6):488-492.

71. El Marroun H, Tiemeier $H$, Steegers EAP, et al. Intrauterine Cannabis Exposure Affects Fetal Growth Trajectories: The Generation $R$ Study. J Am Acad Child Adolesc Psychiatry. 2009;48(12):1173-1181. doi:10.1097/CHI.0b013e3181bfa8ee.

72. Hurd YL, Wang X, Anderson V, Beck O, Minkoff $H$, Dow-Edwards D. Marijuana impairs growth in midgestation fetuses. Neurotoxicol Teratol. 2005;27(2):221-229. doi:10.1016/j.ntt.2004.11.002.

73. Fried PA, Watkinson B, Willan A. Marijuana use during pregnancy and decreased length of gestation. Am J Obstet Gynecol. 1984;150(1):23-27. doi:10.1016/S0002-9378(84)80103-9.

74. Metz TD, Stickrath EH. Marijuana use in pregnancy and lactation: a review of the evidence. Am J Obstet Gynecol. May 2015. doi:10.1016/j.ajog.2015.05.025.

75. Park B, McPartland JM, Glass M. Cannabis, cannabinoids and reproduction. Prostaglandins Leukot Essent Fatty Acids. 2004;70(2):189-197.

76. Gunn JKL, Rosales CB, Center KE, Nuñez AV, Gibson $S J$, Ehiri JE. The effects of prenatal cannabis exposure on fetal development and pregnancy outcomes: a protocol. BMJ Open. 2015;5(3):e007227. doi:10.1136/bmjopen-2014-007227.

77. Shamloul R, Ghanem H. Erectile dysfunction. Lancet Lond Engl. 2013;381(9861):153-165. doi:10.1016/S0140-6736(12)60520-0.

78. Smith AMA, Ferris JA, Simpson JM, Shelley J, Pitts MK, Richters J. Cannabis use and sexual health. J Sex 
Med. 2010;7(2 Pt 1):787-793. doi:10.1111/j.17436109.2009.01453.x.

79. Berrada S, Kadri N, Mechakra-Tahiri S, Nejjari C. Prevalence of erectile dysfunction and its correlates: $a$ population-based study in Morocco. Int J Impot Res. 2003;15(S1):S3-S7. doi:10.1038/sj.ijir.3900968.

80. Johnson SD, Phelps DL, Cottler LB. The association of sexual dysfunction and substance use among a community epidemiological sample. Arch Sex Behav. 2004;33(1):55-63. doi:10.1023/B:ASEB.0000007462.97961.5a.

81. Buffum J. Pharmacosexology: the effects of drugs on sexual function a review. I Psychoactive Drugs. 1982;14(1-2):5-44. doi:10.1080/02791072.1982.10471907.

82. Halikas J, Weller $R$, Morse C. Effects of regular marijuana use on sexual performance. J Psychoactive Drugs. 1982;14(1-2):59-70. doi:10.1080/02791072.1982.10471911.

83. Aversa A, Rossi F, Francomano D, et al. Early endothelial dysfunction as a marker of vasculogenic erectile dysfunction in young habitual cannabis users. Int J Impot Res. 2008;20(6):566-573. doi:10.1038/ijir.2008.43.

84. Shamloul R, Bella AJ. Impact of Cannabis Use on Male Sexual Health. J Sex Med. 2011;8(4):971-975. doi:10.1111/j.1743-6109.2010.02198.x.

85. Freeman ME, Kanyicska B, Lerant A, Nagy G. Prolactin: structure, function, and regulation of secretion. Physiol Rev. 2000;80(4):1523-1631.

86. Ben-Jonathan N, Hnasko R. Dopamine as a Prolactin (PRL) Inhibitor. Endocr Rev. 2001;22(6):724-763. doi:10.1210/edro.22.6.0451.

87. Bromley B, Zimmermann E. Divergent release of prolactin and corticosterone following delta-9tetrahydrocannabinol injection in male rats. In: Federation Proceedings. Vol 35. FEDERATION AMER SOC EXP BIOL 9650 ROCKVILLE PIKE, BETHESDA, MD 20814-3998 USA; 1976:220-220.

88. Murphy LL, Newton SC, Dhali J, Chávez D. Evidence for a direct anterior pituitary site of delta-9tetrahydrocannabinol action. Pharmacol Biochem Behav. 1991;40(3):603-607. doi:10.1016/00913057(91)90370-H.

89. Bonnin A, Ramos JA, Rodríguez de Fonseca F, Cebeira M, Fernández-Ruiz JJ. Acute effects of delta 9tetrahydrocannabinol on tuberoinfundibular dopamine activity, anterior pituitary sensitivity to dopamine and prolactin release vary as a function of estrous cycle. Neuroendocrinology. 1993;58(3):280-286.

90. Fernández-Ruiz JJ, Muñoz RM, Romero J, Villanua MA, Makriyannis A, Ramos JA. Time course of the effects of different cannabimimetics on prolactin and gonadotrophin secretion: evidence for the presence of CB1 receptors in hypothalamic structures and their involvement in the effects of cannabimimetics. Biochem Pharmacol. 1997;53(12):1919-1927.

91. Hughes CL, Everett JW, Tyrey L. $\Delta 9$ Tetrahydrocannabinol Suppression of Prolactin
Secretion in the Rat: Lack of Direct Pituitary Effect. Endocrinology. 1981;109(3):876-880. doi:10.1210/endo-109-3-876.

92. Murphy LL, Steger RW, Smith MS, Bartke A. Effects of delta-9-tetrahydrocannabinol, cannabinol and cannabidiol, alone and in combinations, on luteinizing hormone and prolactin release and on hypothalamic neurotransmitters in the male rat. Neuroendocrinology. 1990;52(4):316-321.

93. Mendelson JH, Mello NK, Ellingboe J. Acute effects of marihuana smoking on prolactin levels in human females. J Pharmacol Exp Ther. 1985;232(1):220-222.

94. Vescovi PP, Pedrazzoni M, Michelini M, Maninetti L, Bernardelli F, Passeri M. Chronic effects of marihuana smoking on luteinizing hormone, follicle-stimulating hormone and prolactin levels in human males. Drug Alcohol Depend. 1992;30(1):59-63. doi:10.1016/03768716(92)90036-C.

95. Mendelson JH, Ellingboe J, Mello NK. Acute effects of natural and synthetic cannabis compounds on prolactin levels in human males. Pharmacol Biochem Behav. 1984;20(1):103-106. doi:10.1016/00913057(84)90109-6.

96. Abel EL. Cannabis: Effects on hunger and thirst. Behav Biol. 1975;15(3):255-281. doi:10.1016/S00916773(75)91684-3.

97. Williams CM, Rogers PJ, Kirkham TC. Hyperphagia in pre-fed rats following oral delta9-THC. Physiol Behav. 1998;65(2):343-346.

98. Williams CM, Kirkham TC. Reversal of delta 9-THC hyperphagia by SR141716 and naloxone but not dexfenfluramine. Pharmacol Biochem Behav. 2002;71(1-2):333-340.

99. Kirkham TC, Williams CM. Endocannabinoids: neuromodulators of food craving. Food Cravings Addict Leatherhead Publ. 2001:85-120.

100. Jamshidi N, Taylor DA. Anandamide administration into the ventromedial hypothalamus stimulates appetite in rats. $\mathrm{Br} J$ Pharmacol. 2001;134(6):1151-1154. doi:10.1038/sj.bjp.0704379.

101. Colombo G, Agabio R, Diaz G, Lobina C, Reali $R$, Gessa GL. Appetite suppression and weight loss after the cannabinoid antagonist SR 141716. Life Sci. 1998;63(8):PL113-PL117.

102. Vickers SP, Webster LJ, Wyatt A, Dourish CT, Kennett GA. Preferential effects of the cannabinoid CB1 receptor antagonist, SR 141716, on food intake and body weight gain of obese (fa/fa) compared to lean Zucker rats. Psychopharmacology (Berl). 2003;167(1):103-111. doi:10.1007/s00213-002-1384-8.

103. de Pasquale A, Costa G, Trovato $A$. The influence of cannabis on glucoregulation. Bull Narc. 1978;30(3):33-41.

104. Greenberg I, Kuehnle J, Mendelson JH, Bernstein JG. Effects of marihuana use on body weight and caloric intake in humans. Psychopharmacology (Berl). 1976;49(1):79-84. 
105. Foltin RW, Brady JV, Fischman MW. Behavioral analysis of marijuana effects on food intake in humans. Pharmacol Biochem Behav. 1986;25(3):577-582.

106. Foltin RW, Fischman MW, Byrne MF. Effects of smoked marijuana on food intake and body weight of humans living in a residential laboratory. Appetite. 1988;11(1):1-14.

107. Arnone M, Maruani J, Chaperon F, et al. Selective inhibition of sucrose and ethanol intake by SR 141716, an antagonist of central cannabinoid (CB1) receptors. Psychopharmacology (Berl). 1997;132(1):104-106.

108. Beal JE, Olson $R$, Laubenstein $L$, et al. Dronabinol as a treatment for anorexia associated with weight loss in patients with AIDS. J Pain Symptom Manage. 1995;10(2):89-97.

109. Le Strat Y, Le Foll B. Obesity and cannabis use: results from 2 representative national surveys. Am J Epidemiol. 2011;174(8):929-933. doi:10.1093/aje/kwr200.

110. Farhat T, Iannotti RJ, Simons-Morton $B$. Overweight, Obesity, Youth, and Health-Risk Behaviors. Am J Prev Med. 2010;38(3):258-267. doi:10.1016/j.amepre.2009.10.038.

111. Rodondi N, Pletcher MJ, Liu K, Hulley SB, Sidney S, Coronary Artery Risk Development in Young Adults (CARDIA) Study. Marijuana use, diet, body mass index, and cardiovascular risk factors (from the CARDIA study). Am J Cardiol. 2006;98(4):478484. doi:10.1016/j.amjcard.2006.03.024.

112. Le H, Gm R. Delta-9-tetrahydrocannabinol and glucose tolerance. Clin Pharmacol Ther. 1974;16(2):297-302.

113. Podolsky S, Pattavina CG, Amaral MA. Effect of Marijuana on the Glucose-Tolerance Test*. Ann N Y Acad Sci. 1971;191(1):54-60. doi:10.1111/j.17496632.1971.tb13986.x.

114. Penner EA, Buettner $H$, Mittleman MA. The impact of marijuana use on glucose, insulin, and insulin resistance among $U S$ adults. Am J Med. 2013;126(7):583-589.

doi:10.1016/j.amjmed.2013.03.002.

115. Muniyappa $R$, Sable $S$, Ouwerkerk $R$, et al. Metabolic effects of chronic cannabis smoking. Diabetes Care. 2013;36(8):2415-2422. doi:10.2337/dc12-2303.

116. Rajavashisth TB, Shaheen M, Norris KC, et al. Decreased prevalence of diabetes in marijuana users: cross-sectional data from the National Health and Nutrition Examination Survey (NHANES) III. BMJ Open. 2012;2:e00494. doi:10.1136/bmjopen-2011000494. 